\title{
Reescrituras burlescas de la tradición clásica en Francia. Paul Scarron
}

\author{
Claudia RUIZ GARCÍA \\ Universidad Nacional Autónoma de México
}

\begin{abstract}
El texto revisa el contexto en que florece la escritura burlesca en Francia (la regencia de Ana de Austria). Se concentra en la importancia y posición de esta literatura durante la elaboración de la doctrina clásica (1630-1660), y analiza en particular la reescritura de Paul Scarron de la Eneida de Virgilio en versión burlesca a partir de criterios como el de imitación, traducción y parodia de los modelos clásicos.
\end{abstract}

PALABRAS ClAVE: tradición clásica, reescritura burlesca, Scarron, Le Virgile travesti, Virgilio, La Eneida.

This textrevises the context of burlesque writing in France (Anne of Austria's regency), andhighlights the importance and position of this type of literatureduring the elaboration of the classical doctrine (1630-1660). In particular, itanalyzes Paul Scarron's burlesque rewriting of Virgil's Aeneid, based on criteriasuch as the imitation, translation and parody of classicalmodels.

KEYWORDS: classical tradition, burlesque rewriting, Scarron, Le Virgile travesti, Virgil, The Aeneid.

Cuando se revisa la historia de la literatura burlesca francesa del siglo XVII, la obra de Paul Scarron se impone como una referencia obligada, para entender la importancia de una producción marginal (Leclerc, 2008: 28), ${ }^{1}$ que le valió el título, atribuido por Theophile Gautier a este autor, de "Homero de la escuela bufona" (Serroy, 1988: 1). $\mathrm{Su}$ quehacer literario es muy variado, pues escribe novelas, cuentos libertinos, piezas de teatro y poesía de circunstancia. ${ }^{2}$ Sin embargo, fue más bien como creador de

\footnotetext{
${ }^{1}$ Sin embargo, este mismo autor, en su obra L'Antiquitpe travestie et la vogue du burlesque en France (1643-1661), hace referencia a uno de los más importantes estudiosos de la producción literaria de este siglo, Antoine Adam, quien se opone a la visión de algunos críticos que prefieren interpretar la tradición burlesca como un movimiento literario completamente al margen del clasicismo doctrinario y académico o como una aberración literaria opuesta a la tradición clásica (28).

${ }^{2}$ Como el poema que escribió a la muerte de su odiada madrastra, conocida como una usurera cuya avaricia era tal que había mandado, por ejemplo, achicar los hoyos de la azucarera: "Epitaphe sur une Dame qui mourut constipée. / Ci-gît qui se plut tant à prendre / Et qui l'avait si bien appris / Qu'elle aima mieux mourir que rendre / un remède qu'elle avait pris" (Leca, 1999: 9). Traducción: "Epitafio a una dama que
} 
epopeyas burlescas que se ganó la admiración de sus contemporáneos, pero también el recelo de figuras de autoridad de su tiempo.

Fue víctima de un severo reumatismo tuberculoso que lo dejó contrahecho y paralítico. Uno de los médicos que lo trató, La Mesnardière, que también era poeta, prescribió en varias ocasiones remedios y drogas que sólo agravaron su mal (Serroy, 1988: 39). Scarron supo sacar un gran provecho de estas desventuras, ya que las utilizó para obtener una pensión de la reina Ana de Austria, esposa de Luis XIII, y de muchas personalidades importantes de la corte, ganándose la compasión de éstas, al describir hasta el mínimo detalle los nefastos efectos de este padecimiento, ya fuera para reírse de sí mismo y hacer reír a su público o congraciarse con él (Leca, 1999: 38).

Antes de dedicarse a escribir epopeyas en esta tónica ya contaba en su haber con una colección de versos burlescos, estilo que había asimilado de poetas de la generación que lo precede, como Marot, pero también de sus coetáneos como Voiture, Ménage, Sarasin y Saint-Amant. Al igual que estos poetas, Scarron, en algún momento de su vida y siguiendo una moda muy gustada, recurre a un estilo bajo y burlón, pero no de manera espontánea, sino por el contrario muy elaborada para demostrar su capacidad para crear agudezas y muestras de ingenio. Lo burlesco traduce en forma bufona situaciones heroicas, pero también puede, por el contrario, utilizar un tono ampuloso y elevado para narrar acontecimientos prosaicos, respetando reglas de versificación, o bien mezclando o alternando pautas propias de la métrica. Consciente del atractivo de este estilo que anteriormente se había denominado grotesco, Scarron escribe posteriormente Le Thyphon (El tifón), que es la primera de una serie de epopeyas compuesta de cinco cantos en versos de ocho pies (Serroy,1988: 3). Este texto sólo cuenta con dos mil trescientos versos, lo que resulta muy breve para que se le considere como un verdadero poema épico. Allí cuenta la lucha de gigantes y dioses, los primeros dirigidos por Tifóny los segundos por Júpiter. Pero estos combates, que ya habían sido referidos por Hesíodo y Apolodoro, son tratados en broma ya que la lengua empleada es popular, cargada de arcaísmos, neologismos y regionalismos, y los dioses se presentan en situaciones poco decorosas. Se busca, como dice Jean Leclerc, volver a vestir a los antiguos de forma moderna y reemplazar los viejos trajes latinos por nuevas vestimentas mejor adaptadas a los intereses del momento (15). Júpiter, por ejemplo, es víctima del abuso de bebidas embriagantes, y Marte, que regresa de Flandes, toma cerveza y fuma tabaco. Tifón y sus compañeros realizan festines pantagruélicos. Además el texto está impregnado de anacronismos, pues Mercurio lee el periódico, el rayo de Júpiter puede hacer caer varios campanarios y se jura sobre el Corán (Leca, 1999: 56). Estos textos de alguna forma preparan el terreno de lo que será la más importante de sus epopeyas burlescas, Le Virgile travesti (El Virgilio paródico). Esta obra cuenta con veinte mil novecientos dieciséis versos; está compuesta de doce cantos y Scarron había prometido a su editor entregar un canto por

murió estreñida / Aquí yace quien se complacía tanto en tomar / Y lo había tan bien aprendido / Que prefirió morir que devolver / el remedio que había tomado". 
mes. Dicha empresa no parecería imposible, pues anteriormente había escrito Jodelet souffleté (Jodelet vapuleado) en tan sólo tres semanas (Leca, 78.) Sin embargo, no mantuvo su promesa, pues tardó cinco años en escribir su versión y dejó el octavo libro inconcluso (Serroy, 1988: 41).

El autor parodia la Eneida de Virgilio y transforma a los dioses y héroes en simples burgueses. A Júpiter se le presenta bonachón; Juno es una chismosa amargada; Venus, una madre complaciente y fácil; Eneas, un devoto llorón, tímido e ingenuo; Anquises, un hablador; Calcas un hipócrita, etcétera. Con este texto es posible, según Serroy, hablar de un género que termina por definirse y ser reconocido como tal. En opinión de este crítico:

Avec le Typhon, en 1644, puis de façon plus systématique avec le Virgile travesti, à partir de 1648, le poète applique ce mélange de la facétie et de l'héroïque à la mythologie et à son genre de prédilection, l'épopée. Le travestissement qui consiste à faire basculer le monde noble et empreint de sérieux de la poésie épique dans celui de la facétie et du comique crée un décalage, une dissonance tonale qui ajoutent une touche d'irrespect à ce qui ne relevait encore que d'un simple esprit de gaité. Le burlesque, avant Scarron, n'était que diversion; avec lui, il devient inversion. On comprend pourquoi dès lors, son œuvre fait école (Serroy, 1988: 4). ${ }^{3}$

De esta forma se impone una moda, que transforma en parodia cualquier texto, incluso el relato de la pasión de Jesucristo en versos burlescos no escapa a esta transformación irreverente (Serroy, 1988: 5). Dicha tendencia alcanza su máximo apogeo en Francia en el momento en que la nobleza se confronta con Mazarino, ${ }^{4}$ ministro de Luis XIV, cuando éste es aún muy joven. Cualquier texto es susceptible de ser reescrito, al grado que el mismo Scarron en su versión de la Eneida, en la dedicatoria del libro $\mathrm{V}$, reconoce que se ha abusado de este procedimiento y asume su responsabilidad diciendo: "Tous ces travestissements de livres, et de mon Virgile tout le premier, ne sont autre chose que des coyonneries"5 (384). Así, Virgilio, Homero y Ovidio son los autores que cuentan con más reescrituras burlescas. La Eneida, por ejemplo, fue reescrita por autores conocidos de la época, como Antoine Furetière, Laurent de Laffemas, Georges

${ }^{3}$ Traducción: "Con el Tifón, en 1644, y después de manera más sistemática con el Virgilio paródico, a partir de 1648, el poeta mezcla el chiste y el heroísmo a la mitología y a su género de predilección, la epopeya. La parodia, que consiste en volcar el mundo noble e impregnado de seriedad, propio de la poesía épica, en uno de chiste y comicidad, crea un desfase, una disonancia tonal que le da un toque de falta de respeto a aquello que lo merece. Así, lo burlesco, antes de Scarron, sólo era diversión, en cambio con él se transforma en inversión. Se entiende por qué a partir de él, su obra hace escuela".

${ }^{4}$ Del apellido de este ministro derivó el término "mazarinade", que se define como una pieza de versos satíricos y burlescos, un panfleto o un libelo en prosa publicado durante el tiempo de la Fronde. La mayoría de las "mazarinades" iban dirigidas contra este ministro, pero también se usó esta palabra para referirse a los escritos que defendían al cardenal de los ataques de los "frondeurs". Otros términos que se registran derivados del apellido del cardenal son: "mazarine, mazariner, mazarineries, mazarinisme y mazarisite" (Bar, 1960: 278-279).

${ }^{5}$ Traducción: "Todas estas parodias de libros, y en primer lugar la de mi Virgilio, no son más que tonterías". 
de Brébeuf, los hermanos Perrault, Du Fresnoy y Barciert (Leclerc, 2008: 17-18), ${ }^{6}$ además de Scarron, quien fue el único que se ganó un lugar dentro de esta tradición y logró eclipsar a sus contemporáneos. Este último se inspira de la Eneide travestita del italiano Giambattista Lalli, ya que desde la época de las dos reinas Médicis, Catalina y María, y posteriormente durante el periodo de Mazarino la cultura italiana ejerce una fuerte influencia en la corte francesa y los medios mundanos. Sobre esta presencia cultural del país vecino resulta interesante detenerse en el libro cuarto de la versión paródica de Scarron, pues en él se narran los amores de Eneas y Dido. No obstante, para el público de la época queda claro que el poeta tal vez busca recrear un rumor que circula entre la opinión pública sobre las posibles relaciones entre la reina Ana de Austria, ya viuda, y Mazarino (Chaunu, 1970: 618). ${ }^{7}$ A éste, el pueblo francés lo detesta, pues en opinión de Leclerc, el ministro encarna todo lo que se puede odiar de los italianos, es decir, una actitud afeminada, cierta cortesía hipócrita, un cuidado por la higiene, así como un gusto desmesurado por el juego, el arte y las riquezas (33-34). Esto explicaría por qué Eneas aparece como un extranjero afeminado y llorón.

En el texto de Virgilio, Dido le explica a su hermana Ana la razón por la cual ha quedado prendada a su nuevo huésped y reconoce a qué grado Eneas la perturba. Así le dice:

Si en mi ánimo no estuviera bien asentado y fijo el propósito y bien inmóvil la voluntad de no unirme jamás a nadie con el vínculo matrimonial, después que el amor primero me defraudó con la muerte, si no sintiera el tedio del tálamo y de la antorcha nupcial, tal vez me haría culpable de rendirme a este solo amor (Canto IV, 110-111).

En la versión paródica este pasaje se presenta de la forma siguiente:

Si je n'avais résolu

De vivre en un état solu

Si je n'étais bien résolue

Après avoir été solue

D'un homme qui me fut si cher,

De ne jamais me rattacher

$\mathrm{Si}$ je ne craignais mariage

Comme un mari fait cocuage

Oui, si je ne l'avais juré,

Que ce nœud qui tient si serre

Ne me serrerait de ma vie. ${ }^{8}$

(Livre IV v 88-99)

\footnotetext{
${ }^{6}$ Además véase el erudito estudio de Francis Bar, Le genre burlesque en France au XVIIe siècle. Etude de Style.

${ }^{7}$ Para este historiador, Mazarino será cardenal sin haber recibido las órdenes y se esposará con la reina Ana de Austria después de la muerte de Luis XIII, y dirigirá la nación francesa de 1643 hasta su muerte en 1661.

${ }^{8}$ Trad.: Si no hubiera resuelto

Quedarme solita

Después de ese hombre
} 
Ana en la versión de Virgilio le responde:

¡Oh tú más que la luz amada por tu hermana! ¿Has de consumir tu juventud en soledad y perpetua tristeza? ¿Penando en soledad malgastarás tu juventud entera? ¿Ni dulces hijos has de conocer ni el galardón de Venus? ¿Crees que de esto se preocupan los manes y las cenizas sepultadas? Sea que ningún otro marido, ni en la Libia, ni de Tiro, se haya apoderado de tu amor doliente; sea que Yarbas haya sido desdeñado y los otros caudillos que la africana tierra, copiosa en triunfos, alimenta; pero ¿lucharás también contra un amor grato? (111).

\section{Scarron reescribe este comentario así:}

Oh chère sœur, que j'aime mieux

Ni que mon cœur, ni que mes yeux,

Sachez de moi, ma sœur ma mie,

Qu'un tantin de polygamie,

Qui que l'on dise, fait grand bien;

Vous vieillirez en moins de rien,

Et, quand vous vous verrez vieillotte,

Vous direz: Peste de la sotte,

D'avoir passé vous jeunes ans,

Pour la crainte des médisants,

Dans le fâcheux état de veuve!

Il n'est rien tel que chose neuve!'

(v. 53-64)

que tanto me gustó

Y por quien juré

No volver a atarme

Pues un marido pone cuernos

Y tal lazo aprieta tanto

Si, si no lo hubiera jurado

No me volvería a apretar.

${ }^{9}$ Trad. Oh querida hermanita que tanto quiero

Más que a mis ojos y corazón

Quiero que sepas manita

Que un poquito de poligamia

Aunque dígase lo que se diga, no hace mal.

Dentro de poco serás una vieja

Y cuando te veas como un vejestorio

Te dirás: tonta de mí

Al haber dejado pasar los años

Por miedo al qué dirán

En el estado horrible de la viudez

No hay nada mejor que probar algo nuevo. 
Scarron, como cualquier autor que se asume como moderno o burlesco ${ }^{10}$ en ese siglo, revisa la elocución y una parte de la invención, pero respeta la trama del relato y la disposición original, como en una verdadera traducción (Leclerc, 15). Estamos entonces frente a una versión, sólo que en otro registro, y asistimos a la transformación de sentimientos nobles en pasiones vulgares. Lo ampuloso de la poesía antigua se reduce al nivel de una poesía más familiar. Scarron recurre al verso octosílabo por ser más flexible ya que interesa ante todo poner el relato al alcance de cualquier público, y despojarlo de su rasgo mítico e inaccesible, para "dégonfler toute prétention, désamorcer tout sérieux et ramener les choses à hauteur de réalité" (Serroy, 1988: 15-16). ${ }^{11}$ El texto de Virgilio, que cuenta con 5,761 versos alcanza los 20,916 en la reescritura de Scarron, pues la tradición burlesca se caracteriza por una tendencia a la amplificación, además de una constante intrusión del autor. Éste dialoga, cuando introduce un paréntesis en el texto, con su modelo o bien con su lector. Tal es caso de los versos 2,585 al 2,590, del libro II. El poeta explica:

(Si les Troyens brûlaient leurs morts.

Au lieu d'en enterrer les corps.

Le poète ici s'entretaille:

Mais, ô bon lecteur! Tout coup vaille,

Il importe peu que Scarron

Altère quelquefois Maron). ${ }^{12}$

El narrador se aparta del relato y comparte con su lector las dificultades que enfrenta, como podría ser respetar las exigencias formales y la rima. El paréntesis funciona para explicar la postura del autor frente al texto fuente y la firme decisión de volver a contarlo, sólo que de otra forma.

Por otra parte, el interés de retomar un relato de la antigüedad y reescribirlo en estilo bufón se entiende como una práctica intertextual muy recurrida; no hay que olvidar que para un clásico escribir es reescribir. Por ello Claudine Nédélec se interroga

\footnotetext{
${ }^{10}$ Pierrre Schoentjes, en la definición que ofrece de "burlesque" en Le Dictionnaire du Littéraire, explica que dentro de la Querelle des Anciens et des Modernes para los partidarios del segundo grupo, donde se sitúa Paul Scarron, el registro burlesco es ampliamente defendido por éstos como una firme reacción a la condena y combate de los "Anciens" frente al grupo de escritores que recurrieron a este registro como una posibilidad de enriquecer la escritura y de reaccionar contra las reglas que imponía el clasicismo.

${ }^{11}$ Traducción: "desinflarlo de cualquier pretensión, desactivar lo serio y llevar las cosas a la altura de la realidad".

${ }^{12}$ Traducción: (Si los troyanos incineraban a sus muertos

En lugar de enterrar sus cuerpos

El poeta aquí se las ve duras,

Pero buen lector! Cualquier cambio lo vale

Poco importa si Scarron

altera algunas veces a Virgilon).
} 
sobre el objetivo primordial de la reescritura de la tradición antigua que busca acercar el texto a un público más amplio y hacerlo más familiar. Para esta especialista:

[...] ces textes ne réclamaient-ils pas justement une attitude de lecteur conscient de la distance envers un chef-d'œuvre de la littérature universelle? Les rendre familiers, proches, les apprivoiser, n'est-ce pas les rendre ordinaires, donc en détruire insidieusement la grandeur (construite par des siècles d'Histoire et de sacralisation littéraires)? De plus, la transposition n'en révélait-elle pas les faiblesses intrinsèques? S'agissaitil alors d'une entreprise de démolition, certes, mais qui ne s'en prenait qu'aux grands de la littérature, êtres de papier tout de même beaucoup moins dangereux que les puissants réels? Mais, en invitant le lecteur à mettre en doute des hiérarchies esthétiques, ne l'invite-t-on pas en mettre en doute aussi les hiérarchies sociales? (Nédélec, 2007: $36-37) \cdot{ }^{13}$

Además debemos entender que para cualquier escritor del siglo XVII la noción de imitación no es de ningún modo antinómica de la noción de originalidad. El autor se apropia de la cultura antigua y la modifica imprimiendo su sello muy particular, que debe entenderse como su aportación, que consiste en erigirse como un mediador a través del cual una obra de la Antigüedad se actualiza por el contacto con un contexto contemporáneo. Se trata, como lo sugiere Schoentjes en Le dictionnaire du Littéraire, de una escritura en palimpsesto que se realiza tanto en la prosa como en el verso. No obstante, Gérard Genette observa que, como cualquier actualización, ésta sólo puede ser momentánea y transitoria ya que después de algunas décadas la parodia pierde su actualidad y por lo tanto su eficacia o se diluye en la distancia histórica (1982: 169181). Situación que no sucede con el texto original, pues se mantiene o perpetúa a pesar de dicha distancia. Es verdad que para valorar una práctica literaria así, el conocimiento de las fuentes es absolutamente indispensable. Si el lector no conoce la obra de Virgilio la parodia se convierte en un simple texto cómico y pierde su dimensión intertextual. El lector debe captar las alusiones literarias y los juegos de desfase entre una materia antigua imitada y una expresión moderna trivial. Es por ello que los autores más conocidos de la antigüedad son los más parodiados. La práctica burlesca se reduce a un entretenimiento o juego erudito que está presente en numerosos géneros poéticos, pero poco a poco se limita al de la epopeya. Dicho género se caracteriza por cierto prestigio pues ocupa ante los ojos de los clásicos el primer lugar de la jerarquía de las formas literarias, es por ello que apela y provoca lo burlesco. En la época clásica, las condiciones históricas e ideológicas para escribir una verdadera epopeya parecen

\footnotetext{
${ }^{13}$ Traducción: ¿Acaso esos textos no exigen precisamente una actitud de lector consciente frente a una obra maestra de la literatura universal? ¿Volverla familiar, cercana, domesticada, no es convertirla en ordinaria, destruyendo con ello la grandeza construida por siglos de Historia y sacralización literarias? Además, ¿la transposición no mostraría debilidades intrínsecas? ¿Se trataría entonces de una empresa de demolición, seguramente, pero que no atacaría a las grandes figuras literarias, seres de papel de cualquier forma menos peligrosos que los poderosos de verdad? Pero, al invitar al lector a cuestionar las jerarquías estéticas ¿no se le invita también a poner en duda las jerarquías sociales?
} 
ya no existir. Es verdad que hay algunos autores, en particular en el Renacimiento, que escriben epopeyas, como es el caso de Ronsard, sin embargo, para el siglo que nos ocupa y el siguiente su interés está más bien en el cuestionamiento o desafío de este tipo de texto bajo su forma burlesca. Al recurrir a este género los autores de esta tradición ponen en tela de juicio una serie de valores, como es el caso del poema burlesco de Voltaire sobre una de las figuras heroicas más importantes de la historia de Francia: Juana de Arco (La Pucelle d'Orléans). ${ }^{14}$ También se pone en duda la supuesta representación de Dios sobre la tierra por medio del monarca, idea que durante el reinado de Ana de Austria es totalmente cuestionable. La posición de los autores paródicos se caracteriza por una postura contestataria, rebelde y susceptible de provocar cierto escándalo. Se colocan muy cerca de las actitudes propias de los filósofos libertinos del siglo, como Cyrano de Bergerac, Gassendi, Charles D’Assoucy, La Motte le Vayer, y otros tantos que también incursionan en el terreno de la literatura ${ }^{15}$ para expresar la necesidad de emanciparse de la tutela de sus maestros, de la tradición y de la ortodoxia, reclamando para el ingenio moderno el derecho a seguir libremente un nuevo camino, fuera de las vías trazadas por los antiguos.

Además los autores paródicos tienen la capacidad de hacer chocar y destruir las ideas recibidas sobre las costumbres en reacción a todo lo que encarna la autoridad. Se invita a una revisión de los modelos antiguos y, en lugar de retomarlos a través de la erudición estéril y una ciega veneración, se sirve de ellos sólo para divertir según los códigos de moda en los salones, que incitan a esconder su aspecto serio o rígido con un velo más alegre, en broma, como una translación deformante y deformada, para un público capaz de apreciar la desacralización impuesta a los clásicos (Leclerc, 2008: 219). Esta burla contra los antiguos sería indisociable, en ese contexto, de un ataque dirigido contra los pedantes y los doctos. Resulta interesante imaginar la reacción de éstos frente a las transformaciones del texto, como ver a los héroes troyanos implorar el ora pro nobis; jurar en nombre de Mahoma; rezar el padre nuestro; citar el Evangelio; desear el peor mal al enemigo como reducirlo a monje castrado. Venus, por ejemplo, saluda a Júpiter con la fórmula árabe "salamalec". Se compara las proezas de estos héroes con los de la tradición judeocristiana, como Goliath y a Roma con la ciudad de

${ }^{14}$ Aunque este filósofo también escribió una epopeya, L'Henriade, con el propósito de exaltar los méritos del rey Enrique IV, quien permitió, gracias a la promulgación del célebre Edicto de Nantes, la convivencia entre católicos y protestantes, después de las luchas fratricidas entre éstos durante una buena parte del siglo XVI.

${ }^{15}$ Baste mencionar la antinovela Le parasite Mormon, escrita por varias manos entre las que es posible identificar a Cyrano de Bergerac, el hijo de La Mothe le Vayer, Charles D'assoucy, Tristan L'Hermite, La Chapelle y el mismo Paul Scarron. Esta antinovela debe leerse más bien como un manifiesto literario, donde se defienden no solamente ideas, sino obras de teatro, poemas y novelas. El texto se abre con una página en blanco reservada al lector donde se explica que la intención de los autores era que se retratara allí a sus amigos, en medio de un banquete, pero como no habían podido conseguir recursos para el festín, juzgaron muy pertinente pedirle al lector potencial que lo supliera por medio de la fuerza de su imaginación. A lo largo del texto los personajes hacen una serie de alusiones críticas a las tradiciones narrativas y se burlan de convenciones retóricas, estructurales, temáticas, etcétera. 
las sotanas. Los personajes se refrescan con cerveza, como en el caso del Tifon, o ingieren ajenjo. Además se presenta a Eneas con su cabello peinado con pomada, perfumado y con una vestimenta afeminada, y señala que espera llegar al territorio donde él y sus acompañantes podrán tener una vida muy "a gogo". Este héroe entretiene a Astianax contándole la historia de "Piel de Asno". Dido maldice a Eneas llamándolo "hijo de puta" y se le describe como a una reina gordinflona, grasosa, vigorosa y muy sana. A veces se le ordena a la tropa ir la "meme" en lugar de mandarla a descansar. Se describe a Lavinia como una joven muy devota y para nada mojigata. Se le augura a Eneas la misión de hacer florecer lo mejor de su raza desde México hasta Calcuta. En ocasiones se baila la pavana o se cantan "vaudevilles".

En suma, esta poesía que recurre a fórmulas bajas y vulgares dialoga de forma irreverente con una tradición que pertenece a los círculos eruditos y más cultos del momento. Pero al mismo tiempo parecería, como bien lo señala Leclerc, que no se reescribe a ciegas. Para este crítico, Scarron intenta crear una cierta rivalidad con Virgilio en el terrero del juego poético, haciendo valer a la vez su facultad de traducción heroica y su capacidad inventiva en cualquier registro (312). Aunque también podríamos decir que desafía a los poetas reconocidos u oficiales de su tiempo, como es el caso de Malherbe. En el libro VII se refiere a él diciendo:

Cependant Junon l'Argienne,

Selon sa coutume ancienne,

D'Argos seule s'en revenait

Dans un joli char qui traînait

Une paire de paons superbes:

Si j'étais un des nos Malberbes,

J'en ferais la description;

Mais j'ai ouï parler Ixion,

Et je sais bien que trop entreprendre

Est le moyen de se méprendre. ${ }^{16}$

(vv. 953-962)

El poeta domina los códigos retóricos, las exigencias estilísticas, las reglas de versificación, sin embargo, se empeña en alejarse del registro de la epopeya seria por uno cómico, para hacer más atractivo este texto a un público que busca en la literatura un

\footnotetext{
${ }^{16}$ Trad.: Sin embargo Juno la Argevina

Según su vieja costumbre

Regresaba sólo de Argos

En un bonito carro que arrastraba

Un par de soberbios pavorreales:

Si fuera uno de nuestros Malherbes

Haría aquí la descripción

Pero he oído hablar de Ixión

Y bien sé que para no equivocarse

Es mejor quedarse calladito.
} 
entretenimiento más ligero. Estamos frente a un periodo de transición entre la cultura renacentista y humanista, que respetó o veneró la tradición clásica, hacia una cultura, la del Siglo de las Luces, mucho más mundana y bien asumida como momento de cambio y de ruptura frontal con dicha tradición.

\section{Obras citadas}

BAR, Francis.1960. Le genre burlesque en France au XVIIe siècle. Etude de Style. París: Editions D'Artrey.

Chaunu, Pierre. 1970. La Civilisation de l'Europe Classique. París: Arthaud.

GenetTE, Gérard. 1982. Palimpsestes, La littérature au second degré. París: Editions du Seuil.

LeCA, Ange Pierre. 1999. Scarron: Le malade de la reine. París: Ëditions Kimé.

LECLERC, Jean. 2008. L'antiquité travestie et la vogue du burlesque en France (1643-1661). Quebec: Presses de l'Université Laval.

Le Dictionnaire du Littéraire. 2002. Dir. Paul Aron, Denis SAINT-JACQUES y Alain VIALA. París: PUF.

NÉDÉLEC, Claudine. 2007. "Burlesque et interprétation". Les Dossiers du Grihl [en línea], les dossiers de Claudine Nédélec, Le XVIIe siècle, mis en ligne le 14 novembre 2007. Consultado: 25 de enero de 2016. URL: <http:/dossiersgrihl. revues.org/329>.

SCARron, Paul. 1988. Le Virgile travesti. Ed. Jean SERroy. París: Garnier.

SERroy, Jean. 1988. "Introduction générale". Paul SCARron. Le Virgile travesti. París: Garnier.

VIRGILIO, 1988. Eneida. Trad. Lorenzo RIBER. Ed. Ángel SIERRA. Madrid: Aguilar. 